\title{
Double lumen tube placement with the Bullard laryngoscope
}

G. Brent Shulman $\mathrm{MD}$, Neil Roy Connelly MD

Purpose: Placement of double lumen tubes (DLTs) in both normal and difficult airways may be considerably more difficult than standard laryngoscopy and intubation using standard tracheal tubes. Alternative techniques to place DLTs have not been uniformly successful and alternative tracheal tubes do not provide the versatility afforded by the DLT. We intubated the tracheas of patients undergoing thoracic procedures requiring DLTs with the Bullard laryngoscope (BL) to determine its efficacy and outline its shortcomings.

Methods: Twenty nine consecutive patients scheduled for general anesthesia requiring DLT were evaluated. The laryngeal view, time to intubation and the reason for any difficulty with intubation were recorded. Any patient who required a second DLT placement had the second attempt performed via standard laryngoscopy.

Results: The time to laryngoscopy was $9 \pm 5 \mathrm{sec}$, and the time to intubation was $28 \pm 10 \mathrm{sec}$. All patients had Cormack scores of grade of I through the BL. The placement of the bronchial lumen of the DLT was found to be in the correct location (left mainstem bronchus) in 9 of 28 patients.

Conclusion: The BL appears to be effective in the placing DLT into the trachea of patients.

Objectif : Le positionnement de tube double lumière (TDL) lors d'intubation normale ou difficile peut être beaucoup plus ardu que la laryngoscopie standard et l'intubation à l'aide de tubes endotrachéaux ordinaires. Les techniques de rechange pour placer les TDL ne sont pas d'égale valeur et les tubes de remplacement ne permettent pas la polyvalence du TDL. On a procédé à l'intubation trachéale de patients qui devaient subir une chirurgie thoracique nécessitant des TDL avec le laryngoscope de Bullard (LB) pour déterminer son efficacité et en souligner les défauts.

Méthode : Vingt-neuf patients successifs devant recevoir une anesthésie générale avec TDL ont été évalués. L'aspect du larynx, le temps d'intubation et la raison de toute difficulté d'intubation possible ont été enregistrés. Chez tout patient qui a eu besoin d'un repositionnement du TDL, on a fait le second essai par laryngoscopie standard.

Résultats : Le temps de la laryngoscopie a été de $9 \pm 5 \mathrm{~s}$, et le temps d'intubation, de $28 \pm 10 \mathrm{~s}$. Tous les patients ont eu des scores de Cormack de qualité I pour le LB. La position de l'ouverture bronchique du TDL a été jugée correcte (bronche principale gauche) chez 9 des 28 patients.

Conclusion : Le LB s'est révélé efficace dans la mise en place du TDL dans la trachée.

From the Department of Anesthesiology, Baystate Medical Center, Tufts University School of Medicine, 759 Chestnut Street, Springfield, MA 01199, USA.

Address correspondence to: Neil Roy Connclly MD, Phone: 413-794-4325; Fax: 413-794-5349; E-mail: NRCONNELLY @AOL.COM Accepted for publication November 30, 1998 


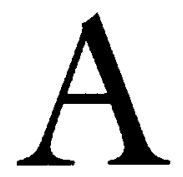

double lumen tube (DLT) is a useful tool for the management of patients undergoing operative thoracic procedures. The gold standard providing unsurpassed lung separation of ventilation is the DLT ${ }^{1}$; it allows the independent administration to each lung of therapy that can be administered via a standard tracheal tube (TT) to both lungs. ${ }^{1}$ Placement of a DLT is more complicated than placement of a standard TT because the DLT is larger in diameter, longer, and has a more fixed shape. An alternative to the DLT for achieving lung separation is the Univent TT (Fuji systems, Tokyo, Japan), which has a bronchial blocker built in to its wall. The Univent tube can be placed with a standard laryngoscope and the lumen accommodates a fibreoptic bronchoscope (FOB) to place the bronchial blocker accurately. The Univent TT, however, lacks the versatility and spectrum of therapy that may be administered through a DLT (e.g. CPAP to the non-ventilated lung, differential PEEP, bronchoscopy of the non-ventilated lung).

An alternative to standard laryngoscopy in placing a DLT is a FOB. However, the limited internal diameter of the bronchial lumen of the DLT limits the FOB to a pediatric model. Furthermore, the longer length of the DLT can make fibreoptic placement difficult.

Intubation with the DLT can be difficult even in patients with "normal" airways and an adequate direct laryngoscopic view. Thus, it has been proposed that a difficult airway is a relative contraindication for DLT placement. $^{2}$ The Bullard laryngoscope (BL) has a number of advantages over direct laryngoscopy to facilitate tracheal intubation in patients with difficult airways. Since the standard stylet of the Bullard laryngoscope has a sufficient length to accept a 28-39 French DLT, we undertook a series of DLT intubations with the $\mathrm{BL}$ to determine whether it was a feasible technique, and whether its use could be considered in patient with "difficult airways."

\section{Methods}

Following institutional review board approval, 29 consecutive thoracic patients scheduled for elective general anesthesia requiring DLT were evaluated. Laryngoscopy in all patients was performed by a single anesthesiologist experienced in the use of the $\mathrm{BL}$ in adults.

An airway examination was performed on all patients and a score based on the Mallampati (Mal) classification was recorded. The BL was prepared by having an appropriately sized DLT placed on a well lubricated modified BL stylet (distal angle to approximately $15^{\circ}$ as described by Crosby $\left.^{3}\right)$. The DLT was placed "back- wards" such that it curved away from the scope (i.e., the curve of the DLT angled it posteriorly) as it slid off the stylet. The DLT, lubricated stylet, and BL were kept warm by wrapping it in a warm blanket attached to a forced air warmer (Bair Hugger, Augustine Medical Inc., Eden Prarie, MN). ${ }^{4}$ Anesthesia was induced with thiopental or propofol and maintained with isoflurane in oxygen. Cisatracurium was used as the muscle relaxant in all patients. Once the vocal cords were visualized the DLT was slid off the stylet. If the DLT contacted a laryngeal structure and could not be advanced in to the glottis, the tube was withdrawn up the stylet and manipulation of the scope was performed to avoid the anatomical structure. Laryngoscopy and intubation were video-taped; the time to view the larynx (defined as the time from picking up the BL until a laryngeal view was obtained) and time to intubate (defined as the time from picking up the BL until the DLT was placed) were determined from the tape. Cormack ${ }^{5}$ grading of the laryngeal view was recorded at intubation. Correct placement of the bronchial lumen of the DLT was determined by FOB. If a patient required a repeat laryngoscopy and intubation, a standard laryngoscope was used to place the second DLT. The same endpoints were recorded for the direct laryngoscopy placement. Data are presented as mean \pm sd (range).

\section{Results}

The mean age of the patients studied was $42 \pm 25 \mathrm{yr}$. In 28 of the 29 patients studied, the trachea was successfully intubated with the BL. Time to laryngoscopy was $9 \pm 5(5-24) \mathrm{sec}$. The time to intubation was 28 $\pm 10(14-55) \mathrm{sec}$. The initial airway examination resulted in $16 \mathrm{Mal} \mathrm{I,} 7 \mathrm{Mal} \mathrm{II}$ and $6 \mathrm{Mal}$ III. All patients had Cormack scores of grade of I through the $\mathrm{BL}$. One trachea could not be intubated using the BL. When direct laryngoscopy and intubation using the 37 French DLT were attempted it also was unsuccessful as the DLT was too large for the glottis.

Two patients had standard laryngoscopy attempted prior to BL. One patient underwent direct laryngoscopy for DLT placement but was unable to have the DLT successfully placed because of a very small mouth opening (secondary to radiation therapy for parotid cancer). In an attempt to manage this difficult intubation, the trachea was successfully intubated with the BL. Another patient presented for thoracic surgery after a staging mediastinoscopy in which tracheal intubation was difficult despite easy mask ventilation: the trachea was intubated using a FOB. Before pulmonary resection, anesthesia was again induced, and direct laryngoscopy with both Miller 2 and MAC 3 blades revealed a Cormack III airway. The $\mathrm{BL}$ was then 
inserted and provided a Cormack I view and the 39 French DLT was introduced in $27 \mathrm{sec}$.

In seven patients the DLT was changed, one due to a damaged cuff and six due to DLTs too small to provide an adequate seal for lung separation. The time for BL intubation in these seven patients was $34 \pm 12 \mathrm{sec}$, and the standard laryngoscopy intubation time was 37 $\pm 22 \mathrm{sec}$.

The bronchial lumen of the DLT was found to be in the correct location (left mainstem bronchus) in 9 of 28 patients.

\section{Discussion}

In this study, the BL was an effective means of placing the DLT. In 28 of 29 patients, the tracheas were successfully intubated with a DLT via the BL. The times for laryngoscopy and intubation were similar to other reports using standard TTs. ${ }^{6-8}$

Previous studies have shown that the BL is an effective means of facilitating intubation ${ }^{6-11}$ and has several advantages over direct laryngoscopy. The BL consistently provides an excellent view of the larynx independent of the Mallampati score and direct laryngeal view. ${ }^{7}$ It requires minimal mouth opening (TT external diameter plus an additional $6.4 \mathrm{~mm}$ for the blade thickness) and substantially less cervical spine movement for an adequate laryngeal view. ${ }^{8,9}$ These advantages should also hold true in its use with DLTs.

To facilitate a neutral aspect of the DLT as it leaves the stylet, the DLT is loaded "backwards" on the stylet and trial advances of the DLT are performed to ensure that no severe angulation of the DLT occurs as it leaves the stylet. If the DLT displays off-centre or anterior deflection as it leaves the stylet, it is rotated around the axis of the stylet until a neutral course is achieved.

One reason for less than half of the tubes being inserted in to the correct bronchus may be the new Mallinckrodt DLT design. The bronchial lumen has been postulated to have a higher incidence of rightsided placement. ${ }^{12}$ Placement to the right side could also have resulted from the intubating technique of the BL. The DLT was loaded "backwards" and, while rotating the DLT off the BL stylet, one may have less precise control in directing the DLT. Improper bronchial lumen placement was quickly and easily corrected with the FOB. Insertion of a left-sided DLT with the BL by the current method has a higher rate of rightsided insertion than does placement with a standard laryngoscope. ${ }^{13}$ An alternative approach to our method of placement could be to advance the DLT off the BL into the mid trachea where it then could be guided fibreoptically into the left mainstem bronchus.
This series has shown that the BL is a useful tool in the placement of DLTs. The technique is similar to the use of the BL with standard TTs. This suggests that the advantages inherent to the BL should still be present with its use with DLT. Further use in patients with difficult airways are necessary to determine if the $\mathrm{BL}$ provides any advantage rather than an alternative means of placing DLTs.

\section{References}

1 Read RC, Friday $C D$, Eason $C N$. Prospective study of the Robertshaw endobronchial catheter in thoracic surgery. Ann Thorac Surg 1977; 24: 156-61.

2 Benumof $J$. Anesthesia for Thoracic Surgery. Philadelphia: WB Saunders, 1987.

3 Crosby ET. Techniques using the Bullard laryngoscope (Letter). Anesth Analg 1995; 81: 1311-20.

4 Dunn SM, Pulai I. Forced air warming can facilitate fiberoptic intubations (Letter). Anesthesiology 1998; 88: 282.

5 Cormack RS, Lebane J. Difficult tracheal intubation in obstetrics. Anaesthesia 1984; 39: 1105-11.

6 Cohn AI, Zornow MH. Awake endotracheal intubation in patients with cervical spine disease: a comparison of the Bullard laryngoscope and the fiberoptic bronchoscope. Anesth Analg 1995; 81: 1283-6.

7 Cooper SD, Benumof JL, Ozaki GT. Evaluation of the Bullard laryngoscope using the new intubating stylet: comparison with conventional laryngoscopy. Anesth Analg 1994; 79: 965-70.

8 Watts $A D J$, Gelb $A W$, Bach DB, Pelz DM. Comparison of the Bullard and MacIntosh laryngoscopes for endotracheal intubation of patients with a potential cervical spine injury. Anesthesiology 1997; 87: 1335-42.

9 Hastings $R H$, Vigil $A C$, Hanna $R$, Yang $B-\Upsilon$, Sartoris $D J$. Cervical spine movement during laryngoscopy with the Bullard, MacIntosh and Miller laryngoscopes. Anesthesiology 1995; 82: 859-69.

10 Shulman $G B$, Connelly NR, Gibson $C$. The adult Bullard laryngoscope in paediatric patients. Can J Anaesth 1997; 44: 969-72.

11 Borland LM, Casselbrant $M$. The Bullard laryngoscope. A new indirect oral laryngoscope (pediatric version). Anesth Analg 1990; 70: 105-8.

12 Virag $R A$, Yabagi $N$, Furuya $H$, et al. Improvement of the left broncho-cath double-lumen tube (Letter). Anesthesiology 1994: 81: 781-2.

13 Klein U, Karzai $W$, Bloos F, et al. Role of fiberoptic bronchoscopy in conjunction with the use of doublelumen tubes for thoracic anesthesia. Anesthesiology 1998; 88: 346-50. 